\title{
A LÍNGUA PORTUGUESA COMO UMA NOVA LÍNGUA CLÁSSICA ${ }^{1}$
}

\author{
Ana Waleska Pollo Campos Mendonça \\ Pontifícia Universidade Católica do Rio de Janeiro, Brasil.
}

\section{Resumo}

Este artigo se propõe a estudar o processo de constituição da Gramática Portuguesa como uma cadeira autônoma, no âmbito das Reformas Pombalinas dos Estudos Menores. Estuda, particularmente, um conjunto documental constituído de uma Lei e Alvará Régio de 1770, que obrigava os professores régios de Gramática Latina a lecionarem previamente a gramática portuguesa a seus alunos. Esses documentos se articulam com a controvérsia que opôs a gramática dos oratorianos à dos jesuítas, no que se refere à língua na qual se deveria ensinar o Latim. Esta lei foi, posteriormente, complementada com a criação de uma cadeira autônoma de Português e de outras línguas modernas. Tal processo representou uma mudança significativa no estatuto do Português e do próprio Latim no âmbito dos estudos secundários e é uma expressão da dimensão modernizadora das reformas pombalinas no que se refere à afirmação da identidade nacional.

Palavras-chave: reformas pombalinas, estudos secundários, ensino da língua portuguesa, identidade nacional.

\section{PORTUGUESE LANGUAGE AS A NEW CLASSICAL LANGUAGE}

\section{Abstract}

This work intends to study the process of constitution of Portuguese Grammar as an autonomous chair in the context of Pombaline Reforms of Minor Studies. It focuses on a set of documents constituted of a Law and Royal Warrant from 1770 that compels the royal professors of Latin grammar to previously teach Portuguese grammar to their pupils. Those documents articulate to the controversy that opposes the Oratorians grammar to that used by Jesuits, refering to the language through which the teaching of Latin should be put trough. That law will be later complemented by the creation of an autonomous chair of Portuguese Grammar and other chairs of modern languages. This process implies a meaningful change in the status of Portuguese, and

\footnotetext{
${ }^{1}$ Este artigo se origina de trabalho apresentado no $33^{\circ}$ Ische, realizado em San Luis Potosí, México, em julho de 2011. Uma versão reduzida do mesmo está incluída no CDRom referente ao evento.
} 
even Latin itself, within the field of secondary studies, that is an expression of the modernizing dimension of the pombaline reforms, regarding the affirmation of national identity.

Key-words: pombaline reforms, secondary studies, portuguese teaching, national identity.

\section{LA LENGUA PORTUGUESA COMO UNA NUEVA LENGUA CLÁSICA}

\section{Resumen}

El trabajo se propone a estudiar el proceso de constitución de la Gramatica Portuguesa como uma disciplina autónoma, en el ambito da las Reformas Pombalinas de los Estudios Menores. Su foco especifico es um conjunto documental que se constituye de uma ley y un Alvara Regio de 1770, que obligava a los profesores regios de gramática latina a enseñar previamente a sus discípulos la gramática portuguesa. Esta documentación se relaciona con la polémica en torno a las gramáticas latinas de los oratorianos y de los jesuitas, respeto a la lengua con la que se debería desarrollar la enseñanza del Latin. Esta ley fue posteriormente complementada por medio de la concesión de licencia para la enseñanza de Portugues, como disciplina claramente distinta al Latín y de otras lenguas modernas. Tales cambios le otorgaron un nuevo estatus a la lengua portuguesa y, claro está, a la lengua latina, que es una expresión de la dimensión modernizadora de las reformas pombalinas, en el que se refiere a la afirmación de la identidad nacional.

Palabras-clave: reformas pombalinas, enseñanza secundaria, lengua portuguesa, identidad nacional

\section{LA LANGUE PORTUGAISE COMME UNE NOUVELLE LANGUE CLASSIQUE}

\section{Résume}

L'objectif de ce travail est d'étudier le procès de constitution de la Grammaire Portugaise comme une discipline autonome, au sein de La Réforme Pombaline des Études Mineures. II étudie un ensemble de documents qui s'est constitué d'une loi et d'un Édit Royal de 1770, qui obligeait les professeurs royaux de Grammaire Latine à enseigner premièrement à ses élèves la grammaire portugaise. Cette documentation se relie à la polemique qui s'est établie entre les grammaires latines des oratoriens et des jésuites, autour de la langue que l'on doit utiliser pour enseigner le Latin. Cette loi a été postérieurement complétée au moyen de la concession de licence pour l'enseignement du Portugais, comme une discipline clairement distincte du Latin, et d'autres langues modernes. Ce processus a provoqué un changement en ce qui concerne le statut de la langue portugaise et aussi de la langue latine et il est une expression de l'éffort de modernisation de la reforme pombaline du point de vue de l'affirmation de l'identité nationale.

Mots-clé: reformes pombalines, études secondaires, enseignement de la langue portugaise, identité nationale. 
$\mathrm{O}$ presente trabalho se vincula a uma pesquisa sobre as Reformas Pombalinas da Instrução Pública e, em especial, dos chamados estudos menores $^{2}$, cujo foco específico foi a reforma dos estudos secundários e, particularmente, seu impacto no processo de profissionalização do professor.

Cumpre destacar a esse respeito que utilizo o termo estudos secundários com o sentido que Ihe é atribuído por Banha de Andrade (1981 e 1984), compreendendo, especificamente, as aulas régias de Gramática Latina, Grego, Retórica e Filosofia, matérias que corresponderiam nas suas linhas gerais ao currículo humanístico dos colégios jesuíticos, e excluindo-se as aulas de ler e escrever e contar. No entanto, é necessário ressaltar que a todas as aulas régias se aplicava, no contexto das reformas pombalinas, a designação genérica de estudos menores.

$\mathrm{O}$ trabalho não se vincula diretamente com as questões centrais que orientaram a referida pesquisa cujo foco, como se afirmou acima, foi o professor. Mas resulta de um desses pequenos desvios a que a própria pesquisa documental nos obriga, se estamos suficientemente abertos aos achados inesperados com que às vezes nos defrontamos.

O trabalho se propõe a estudar o processo de constituição da Gramática Portuguesa como uma cadeira autônoma no contexto da Reforma Pombalina dos Estudos Menores e se debruça, particularmente, sobre um conjunto documental localizado no Arquivo Nacional da Torre do Tombo, em Lisboa, que, por estar ainda muito pouco referido na historiografia referente às reformas pombalinas, bem como pelas razões que tentarei explicitar, chamou-me particularmente a atenção.

\section{As Reformas Pombalinas dos Estudos Menores ${ }^{3}$}

Afora algumas iniciativas de caráter mais pontual, embora não menos importantes, como a criação, em 1759, de uma Aula do Comércio, em Lisboa, para a educação dos filhos da burguesia comercial emergente, de uma Aula Náutica, no Porto, em 1762, voltada para a formação de marinheiros mercantes, e do Colégio Real dos Nobres, em 1766, data da abertura solene do Colégio, embora seus Estatutos tenham sido publicados em 1761, para a educação da nobreza, a reforma dos estudos menores em Portugal se desenvolveu em dois momentos distintos que se iniciam, respectivamente, com a promulgação do Alvará Régio de 28 de junho de 1759, que cria as aulas régias de Gramática Latina, Retórica e Grego, e da lei de 6 de novembro de 1772, que cria as aulas régias de leitura, escrita e cálculo, além da cadeira de Filosofia.

A Reforma de 1759 se constituiu em uma conseqüência direta da expulsão dos jesuítas dos territórios portugueses e visava à substituição do sistema escolar jesuítico, de proporções bastante significativas para a época, por um sistema de aulas e de professores régios controlados pelo Estado. Não se instituía propriamente um sistema

\footnotetext{
${ }^{2}$ A pesquisa intitulada $A$ reforma pombalina dos estudos secundários e seu impacto no processo de profissionalização do professor foi iniciada por ocasião de um estágio de pós-doutoramento em Portugal, com o professor Rogério Fernandes, da Universidade de Lisboa, e, posteriormente, incorporada ao projeto de intercâmbio entre pesquisadores brasileiros e portugueses História da profissão Docente no Brasil e em Portugal: aproximações e distanciamentos, desenvolvido entre 2007 e 2010 e financiado pelos governos brasileiro e português, no âmbito do programa Capes/FCT.

${ }^{3}$ Essa parte introdutória do texto retoma, em parte, alguns aspectos já trabalhados em artigos anteriores da autora sobre as reformas pombalinas, mas têm o objetivo de situar a temática em questão.
} 
escolar $^{4}$ alternativo mas, fundamentalmente, um quadro de professores avalizados pelo Estado, já que cada professor selecionado, pago e fiscalizado pelo Estado deveria prover a sua própria classe (aula ou escola) sendo, em alguns casos, subsidiado para isso por meio de uma verba adicional para o aluguel do espaço por ele utilizado.

Criou-se o cargo de diretor geral dos Estudos, entregue a D. Tomás de Almeida, Principal da Igreja de Lisboa, que nele permaneceu até o ano de 1772. Ao diretor competiam quatro funções essenciais: a coordenação dos estudos, a elaboração de um relatório anual sobre a situação das aulas régias, a inspeção dos professores e a administração das aulas. No desempenho das suas funções, o diretor geral estabeleceu, desde logo, por todo o território português e domínios, uma rede, inicialmente de informadores e, posteriormente, de comissários, escolhidos no meio judicial e eclesiástico, aos quais delegava uma série de atribuições, entre elas a responsabilidade pela organização dos exames públicos para a seleção dos professores régios e o credenciamento dos mestres particulares, a quem também passava a aplicar-se o controle do Estado.

A reforma de 1772 viria a completar o processo iniciado em 1759, reformulando algumas das medidas tomadas e estendendo a reforma também ao ensino das primeiras letras. Extinguiu-se o cargo de diretor geral e a coordenação dos estudos menores passou para as mãos da Real Mesa Censória. Com a criação do subsídio literário ${ }^{5}$ garantiu-se a existência de uma fonte regular de recursos para a manutenção do sistema, o que veio a permitir a sua ampliação e consolidação.

A Real Mesa Censória foi criada por alvará régio, em abril de 1768, no âmbito do conjunto de medidas tomadas pelo Conde de Oeiras, futuro Marquês de Pombal, para cercear os privilégios e a influência da Igreja nas atividades da vida política e cultural do país, das quais fazem parte, igualmente, as reformas da instrução pública de que se está tratando. A nova instituição possuía, entre outras atribuições, a "jurisdição privativa e exclusiva, em tudo o que pertence ao exame, aprovação e reprovação dos livros, e papéis, que já se acham introduzidos nestes Reinos, e seus domínios” ou que neles pretendessem entrar, bem como o poder de conceder licenças de comercialização, impressão, reimpressão e encadernação de livros e papéis volantes, além da capacidade de autorizar a posse e a leitura de livros proibidos em Portugal e o encargo da reforma do índice expurgatório dos livros (apud ANTT. Direção dos Serviços de Arquitetura e Inventário. Real Mesa Censória. Inventário Preliminar. Lisboa, março de 1994, p. 10). É esta instituição que, a partir da publicação do Alvará de 4/06/1771, assume:

toda a administração e direção dos estudos das escolas menores destes Reinos e seus Domínios, incluindo nesta administração não só o Real Colégio dos Nobres, mas todos e quaisquer outros colégios e magistérios que eu for mandado erigir, para as primeiras idades. (apud Banha de Andrade, 1981, p. 599)

\footnotetext{
${ }^{4}$ A esse respeito, cumpre destacar a importância atribuída por Julia (2001) aos colégios jesuítas, enquanto expressão da escola moderna, seja por seu caráter de um espaço diferenciado, com um mobiliário e material específicos, seja pela organização dos cursos em classes separadas, marcando a progressão em níveis, seja pela existência de um corpo profissional especializado. As duas primeiras dimensões não são consideradas na reforma pombalina.

5 Trata-se de um imposto criado por D. José I, por lei de 10/12/1772, especialmente destinado à manutenção do ensino público em Portugal e domínios.
} 
Esta situação permanece durante o reinado de D. Maria I, até $1794^{6}$, quando a direção dos estudos menores foi transferida para Coimbra, passando a Universidade a centralizar a administração dos diferentes ramos do ensino público e configurar uma mudança efetiva na forma como tais estudos eram geridos até então.

De uma forma geral, os historiadores da educação portugueses e brasileiros, que têm se debruçado sobre essa temática, ressaltam o caráter pioneiro das reformas do ensino empreendidas por Pombal. Tomo aqui as palavras de Nóvoa (1987) que afirma, referindo-se às reformas pombalinas, ser "inegável que a estruturação de um sistema de ensino estatal semelhante aos que existem atualmente é um fato inédito no panorama da educação européia anterior à Revolução Francesa" (p. 136). Chama a atenção, em contraponto, o quase absoluto silêncio da historiografia da educação européia sobre o feito português.

No entanto, o que me interessa aqui, particularmente, são outras características atribuídas pela historiografia a essas reformas e que me parecem marcar a argumentação utilizada nos documentos analisados.

Ao fazer uma revisão dos principais autores que se debruçaram sobre as reformas pombalinas da educação, Cardoso (2002) destaca, por um lado, o consenso em torno da filiação das reformas ao ideário das Luzes, mas aponta também para alguns dos fatores internos ao reinado de $\mathrm{D}$. José I, que motivaram a decisão de Pombal de voltar-se para a educação e de implementar um sistema de ensino de caráter estatal. Para esta autora,

a criação de um sistema de ensino durante o reinado de $\mathrm{D}$. José I, deve ser compreendida no contexto de implantação do Despotismo Esclarecido em Portugal, caminho político escolhido para conciliar a tarefa de modernizar o país, com a preservação da Monarquia absolutista. (Cardoso, 2002, p. 108)

Desse ponto de vista, é preciso considerar que há um conjunto de fatores, de ordem econômica, política, ideológica e cultural que justificam não só o fato de se ter privilegiado, nesse contexto específico, a reforma do ensino, mas do próprio encaminhamento que foi dado a ela.

Remetendo-se ao confronto com a Companhia de Jesus, que está na gênese das reformas pombalinas, Falcon (1982) alerta para o caráter peculiar do pombalismo enquanto expressão da influência das Luzes, em Portugal. Para ele, não se pode cogitar de forma alguma de generalizar a campanha antijesuítica e muito menos de

convertê-la em algo como um movimento francamente irreligioso, ou simplesmente deísta, segundo os padrões vigentes além-Pireneus. Era em nome da própria religião, era em favor da Igreja que o discurso reformista e secularizador justificava a prática hostil aos jesuítas. (p. 429430)

\footnotetext{
${ }^{6}$ Cumpre observar, entretanto, que em junho de 1787, a Real Mesa Censória foi substituída pela Real Mesa da Comissão Geral sobre o Exame e Censura dos Livros, criada para ampliar as funções da primeira, no contexto do processo de reaproximação com o Papado e conseqüente acréscimo da influência eclesiástica na Corte, que marcam o reinado de D. Maria I.
} 
A esse respeito, Falcon (1982) afirma, aliás, categoricamente, que: "a Igreja, uma vez conservada nos seus verdadeiros limites, não devia ser considerada apenas como permitida, mas como absolutamente necessária" (p. 430), admitindo como uma prova evidente dessa afirmativa a colaboração ativa de determinadas ordens religiosas, como é o caso dos oratorianos, nas reformas de ensino. Uma chave interessante de interpretação a respeito dessa questão é proposta por Banha de Andrade, quando aponta para uma marca anti-congregacionista das reformas $^{7}$, ao menos no seu primeiro momento, em contraposição a um caráter propriamente anti-religioso, algumas vezes, erroneamente atribuído a elas.

Retomando Falcon (1982), pode-se afirmar, a meu ver, que o que se queria era efetivamente "uma cultura moderna, sob a égide do Estado secular, mas sobre uma base espiritual, religiosa" (p. 430).

Esta questão se articula com outra peculiaridade apontada por esse mesmo autor: o ecletismo como marca registrada da prática ilustrada em Portugal. É exatamente esse ecletismo teórico e, principalmente, pragmático, que vai permitir conciliar fé e ciência, tradição e inovação, teocentrismo e antropocentrismo. Como afirma Falcon (1982), "predomina em quase todos os casos o meio termo, a cautela diante das inovações excessivas, o receio do desconhecido que o seja em demasia" (p. 431). A própria atribuição da direção dos estudos à Real Mesa Censória, a partir de 1771, já é um forte indicativo dessa disposição.

Já em trabalho anterior sobre as Reformas Pombalinas da Instrução Pública, Ramos de Carvalho (1978), para quem tais reformas constituem "expressão altamente significativa do iluminismo português" (p. 25), afirmava que

nelas se encontra substanciado um programa pedagógico que, se por um lado, representa o reflexo das idéias que agitavam a mentalidade européia, por outro traduz, nas condições da vida peninsular, motivos, preocupações e problemas tipicamente lusitanos. (p. 25)

Citando Cabral de Moncada (1941), ressalta o caráter peculiar do iluminismo português, que "foi essencialmente reformismo e pedagogismo", já que "o seu espírito era não revolucionário, nem anti-histórico, nem irreligioso como o francês; mas essencialmente progressista, reformista, nacionalista e humanista", mais próximo do iluminismo italiano, "essencialmente cristão e católico" (apud Carvalho, 1978, p. 26-27).

Para Ramos de Carvalho, as reformas pombalinas se constituíram, sem dúvida, em um esforço de secularização das instituições, mas uma secularização "a meio caminho da laicização" (1978, p. 29) ${ }^{8}$. Desse ponto de vista, também Carvalho aponta o ecletismo como uma marca registrada das reformas de ensino, particularmente no que se refere às mudanças introduzidas nos estudos filosóficos. Por outro lado, assinala com força a vinculação do que chama o "programa pedagógico do pombalismo ao imperativo do

\footnotetext{
${ }^{7}$ No sentido de que não só se retiram os privilégios que detinham as congregações religiosas, no caso do ensino, mas de que, ao menos no primeiro momento das reformas, evitam-se nomear não só ex-jesuítas, mas frades, de uma forma geral.

${ }^{8}$ A esse respeito é particularmente iluminadora a distinção que Catroga (2006) estabelece entre os termos secularização e laicização. Nesse sentido, as reformas pombalinas são uma expressão do processo de secularização do Estado, mas elas não são laicizantes.
} 
regalismo doutrinário do tempo" (1978, p. 138). Para ele, as reformas de ensino tinham o objetivo último de "criar a escola útil aos fins do Estado" e que, portanto, "antes de servir aos interesses da fé, servisse aos imperativos da Coroa" (idid., p. 139).

Particularmente sugestiva a esse respeito é a argumentação de D. Tomas de Almeida, primeiro diretor geral dos Estudos, em carta enviada aos comissários por ele nomeados, com instruções sobre como agir na implementação das reformas. D. Tomas recomendava não admitir os frades "à pertença destes magistérios", alegando não só a precariedade da sua instrução, mas a impossibilidade de sujeição direta à sua autoridade. Nas suas próprias palavras: "eu quero os meus súditos, que S. Mag.e me confiou nesta Direção, inteiramente sujeitos a mim, sem a exceção, que é o primeiro patrimônio dos Frades", condição, a seu ver, "prejudicial à Republica" (Instrução n. 8 da Carta de Ofício remetida pelo diretor geral aos seus comissários em 6/1/1760, apud Banha de Andrade, 1981, p. 216-217).

Nóvoa (1987), igualmente, endossa este ponto de vista ao ressaltar que, no contexto das reformas pombalinas,

a luta contra os jesuítas deve ser encarada à luz da instituição de um sistema absolutista, dotado de uma máquina administrativa fortemente centralizada, que não pode tolerar o poder dos jesuítas, enquanto um verdadeiro Estado no interior do Estado. (p. 126)

Na perspectiva de Falcon (1982),

o combate antijesuítico foi a luta em prol da afirmação de uma autoridade real, civil, laica, sobre uma autoridade eclesiástica que viera até então mantendo e ampliando sua influência e seu controle, dos mais completos por sinal, por intermédio de seus homens e de suas idéias, sobre a sociedade e sobre o estado, moldando-os à sua imagem e plasmando-os segundo os seus princípios, sua ideologia, e mantendo vigilância incessante contra todos e contra tudo que se constituísse em ameaça a tal hegemonia. (p. 425)

São essas características, aparentemente contraditórias que, a meu ver, se manifestam de forma quase exemplar na documentação analisada e que pretendo explorar mais à frente.

É nesse contexto que deve ser compreendido o processo de afirmação da língua portuguesa face à língua latina, objeto particular do trabalho.

Em um artigo recentemente publicado, um dos poucos que localizei que se debruçam sobre parte da documentação em questão, Barboza (2010) chama atenção para o fato de que

a preocupação com a valorização da língua portuguesa como um bem cultural desponta no cerne das questões sobre a nacionalidade, desde o século $\mathrm{XVI}$, quando o Estado português ambiciona não só conquistar novos territórios e estender o seu comércio, mas também disseminar a língua portuguesa em seus domínios. (p. 299)

Reportando-se aos antecedentes do Alvará de 1770, remete-se à Lei do Diretório dos Índios, de 1757. Por essa lei, impunha-se a língua portuguesa como língua nacional 
no Estado do Grão-Pará e Maranhão, em detrimento da língua geral, habitualmente falada e ensinada nos colégios jesuíticos instalados no Brasil. Como assinala outra autora (Barbosa, 2010), esta lei apenas ratificava o estabelecido na lei de 7/6/1755, que abolira a administração temporal dos jesuítas sobre os índios desse Estado. De fato, aí se situava, sem dúvida, um dos pontos de tensão entre Sebastião José de Carvalho e Melo, o futuro Marquês de Pombal, e a Companhia de Jesus, pois a língua portuguesa não era um instrumento privilegiado pelos padres jesuítas no processo de conversão dos indígenas, já que sua maior preocupação era "normatizar a língua do colonizado para que assim pudesse persuadi-lo e convertê-lo para o cristianismo através do seu próprio sistema lingüístico" (Barboza, 2010, p. 303).

\section{O documento}

Quase ao final da pesquisa documental junto ao Arquivo da Torre do Tombo, localizei, no Catálogo 572 da Real Mesa Censória, na série Administração dos Estudos Menores, livro 2, um documento que me chamou a atenção por não ter encontrado nenhuma referência a ele na bibliografia até então consultada. O livro em questão, classificado sob o título de Registo de leis, decretos e avisos recebidos pela Mesa (17681775), possui uma estrutura peculiar e, na verdade, compreende dois livros distintos: um Livro de Registos de Bulas Pontifícias, Breves Apostólicos e Licenças e um Livro de Leis, Decretos, Alvarás, Cartas e Avisos. Foi nesse segundo livro que se localizou uma Lei e Alvará Régio de 1770, que obrigava os professores régios de Gramática Latina a ensinarem previamente a seus discípulos a Gramática Portuguesa. Relacionando tal documento com o restante da documentação já levantada, foi possível localizar a consulta da qual se originou a Lei e Alvará e o parecer do informante, frei Joaquim de Sant'Anna (livro 19, da série Gestão de Assuntos Diversos, da Real Mesa Censória).

Qual o interesse deste conjunto documental?

Antes mesmo de entrar na análise propriamente dita dos documentos, uma questão preliminar chamou-me a atenção. A lei e o alvará representam uma clara interferência da Real Mesa Censória nos assuntos referentes à instrução pública, num momento em que a direção geral dos estudos ainda se encontrava nas mãos de D. Tomas de Almeida. Com efeito e, como o próprio autor assinala, pode-se perceber na documentação levantada por Banha de Andrade (1981) que, ao final do seu mandato, D. Tomás já não gozava da plena confiança de Pombal. O seu desprestígio fica claramente evidenciado no tom melancólico que marca os seus últimos relatórios anuais, em que se queixa amargamente das demandas não atendidas.

Igualmente, é representativo de uma espécie de apagamento desse primeiro momento das reformas de ensino, o tom inaugural que marca a lei de 1772 , embora se faça referência explícita à regulamentação anterior.

Por outro lado, o fato de que esta documentação, portanto, se situa numa espécie de limbo, entre os dois momentos decisivos da reforma dos estudos menores, poderia justificar o quase absoluto silêncio sobre esta medida, a meu ver, fortemente expressiva do projeto reformador de Pombal. O próprio Banha de Andrade que a cita em uma de suas obras sobre Verney, como se verá a seguir, não a incluiu no seu extensivo levantamento da documentação referente ao primeiro momento das reformas. 
Chamou-me a atenção, em seguida, a existência de certo descompasso entre a consulta originalmente encaminhada à Mesa e o teor da lei e alvará que dela se originaram. A consulta original resultou de uma petição encaminhada pelo bacharel Antonio Joze dos Reis Lobato $^{9}$, que havia escrito uma nova Gramática da Língua Portuguesa e que solicitava que a mesma fosse recomendada aos mestres de Latinidade, bem como utilizada nas escolas de ler e escrever. A argumentação do informante é especialmente interessante.

Este recomenda a utilização da referida gramática, alegando que não só era importante que os discípulos de gramática latina "falem e escrevam com pureza a Língua Materna", quanto que aprendam outras línguas vivas e mortas e que, para isto, o aprendizado da gramática portuguesa também ajuda, já que esta é a "mesma de todas as outras línguas". Ao longo do seu parecer, apela para o exemplo dos gregos e romanos, "que cultivavam com cuidado as suas línguas" e afirma enfaticamente que as línguas vernáculas como a língua francesa e a portuguesa já chegaram a um grau de "sabedoria e esplendor" que, praticamente, as equipara às línguas clássicas.

É significativo que, por outro lado, não recomende o ensino da Gramática Portuguesa "aos meninos das escolas de ler e escrever, em parte pela pouca habilidade dos Mestres, que não seriam capazes de instruí-los cientificamente nesse conhecimento" e, em parte, pela própria imaturidade dos discípulos. Desta forma, marca-se com clareza a diferença entre o ensino das primeiras letras (o ler, escrever e contar) e o ensino da gramática portuguesa, que assumia um status superior.

O parecer final da Mesa é favorável ao solicitante, constando no verso do mesmo uma resolução, com a rubrica de Sua Majestade, que estabelece que os "Mestres de Gramatica Latina, quando receberem os discípulos [para] ensinarem os instruam previamente por tempo de seis meses nesta gramática", e determina que "suba Alvará nesta conformidade".

Com efeito, em 30/9/1770, El Rei D. José I assinava, no Palácio da Ajuda, a "Lei para que nas classes de latinidade sejam os mestres obrigados quando receberem discípulos a instruí-los previamente na gramática portuguesa", à qual se anexava alvará que explicitava que o ensino se faria com base na Gramática Portuguesa composta por Antonio Joze dos Reis Lobato, estabelecendo-se igualmente, que se deveria abolir para sempre

das escolas de ler e escrever o prejudicial abuso dos processos religiosos e sentenças, que até agora neles se liam e que em seu lugar se ensinem os meninos por impressos ou manuscritos, de diferentes naturezas e especialmente pelo catecismo de Montpellier. (ANTT. Real Mesa Censória. Livro 2. Registo de leis, decretos e avisos recebidos pela Mesa (17681775). F. 56) ${ }^{10}$

\footnotetext{
${ }^{9}$ ANTT. Real Mesa Censória. Livro 19, Registo de consultas encaminhadas à Mesa, p. 106-108. Há indícios de que se trata, na verdade, de um pseudônimo do padre oratoriano António Pereira Figueiredo, apontado como figura importante do iluminismo português e colaborador de Pombal. A esse respeito, ver Oliveira (2010) e Asunção (1997).

10 Optou-se, no caso das citações, por atualizar a ortografia, de forma a tornar a leitura do texto mais acessível.
} 
O texto da lei, de que transcrevo a seguir um longo trecho, retoma a argumentação utilizada pelo informante, frei Joaquim de Sant'Anna, em seu parecer anteriormente referido:

Sendo a correção das línguas nacionais um dos objetos mais atendíveis para a cultura dos povos civilizados, por dependerem dela a clareza, a energia e a magestade com que devem estabelecer as Leis, persuadir a verdade da Religião e fazer úteis e agradáveis os escritos. Sendo pelo contrário a barbaridade das línguas a que manifesta a ignorância das nações; e não havendo meio que mais possa contribuir para polir e aperfeiçoar qualquer idioma e desterrar dele esta rudez, do que a aplicação da mocidade ao estudo da Gramática da sua própria língua; porque sabendo-a por princípios e não por mero instinto e habito, se costuma a falar e escrever com pureza, evitando aqueles erros que tanto desfiguraram a nobreza dos pensamentos, e vem a adquirir-se com maior facilidade, e sem perda de tempo a perfeita inteligência de outras diferentes línguas, pois que tendo todas princípios comuns, acharão nela os principiantes menos que estudar todos os rudimentos que levarem sabidos na materna. De sorte que o referido método e espírito da educação foi capaz de elevar as línguas Grega e Romana ao grau de gosto e perfeição em que se viram nos formosos séculos de Atenas e Roma, e que bem testemunham as excelentes e inimitáveis obras que deles ainda nos restam. Conformando-me Eu com o exemplo de outras nações iluminadas, e desejando, quanto em Mim, adiantar a cultura da língua Portuguesa nestes meus Reinos e Domínios, para que neles possa haver vassalos úteis ao Estado, Sou servido ordenar que os mestres da língua latina, quando receberem nas suas classes os discípulos para tha ensinarem, os instruam previamente, por tempo de seis meses, se tantos forem necessários para a instrução dos alunos, na Gramática Portuguesa, composta por Antonio Jozé dos Reis Lobato. (ANTT. Real Mesa Censória. Livro 2. Registo de leis, decretos e avisos recebidos pela Mesa (17681775). F. 55 e verso)

Destaca-se, dessa argumentação, a preocupação com o aperfeiçoamento da língua nacional para superar a barbárie e equipará-la às línguas clássicas, parâmetro e argumento de autoridade e, por outro lado, a afirmação que o estudo da Gramática da própria língua facilita, igualmente, o aprendizado das demais. Fica, portanto, evidenciada a questão da centralidade da língua nacional no âmbito do projeto ilustrado de D. José I e de seu ministro.

Importa destacar que argumentação semelhante já era utilizada para defender o ensino da Gramática Latina, por intermédio da língua vernácula, no Alvará Régio de 1759 e na Instrução para os Professores de Gramática Latina. ${ }^{11}$ Afirma-se no seu parágrafo IV:

Todos os homens sábios uniformemente confessam - remete-se a Rolin, Lami e Walch. - que deve ser em vulgar o método para aprender os preceitos da Gramática, pois não há maior absurdo que intentar aprender

\footnotetext{
${ }^{11}$ As Instruçoens para os Professores de Grammatica Latina, Grega, Hebraica, e de Rhetorica, ordenadas e mandadas publicar, por El Rey Nosso Senhor para o uso das Escolas novamente fundadas nestes Reinos, e seus Dominios, de 28/06/1759, constituem, com o Alvará régio que lhe deu força de decreto, os diplomas fundamentais da primeira fase da Reforma Pombalina. Definem os princípios, os métodos, e, inclusive, estabelecem os compêndios a serem utilizados por alunos e professores, nas diferentes cadeiras estabelecidas.
} 
uma língua, no mesmo idioma que se desconhece. (apud Banha de Andrade, 1981, p. 84-85)

Igualmente se estabelece no parágrafo $\mathrm{VI}$ :

Para que os estudantes vão percebendo, com mais facilidade, os princípios da Gramática Latina, é útil que os Professores Ihes vão dando uma noção da Portuguesa advertindo-lhes tudo aquilo em que tem alguma analogia com a Latina. (apud Banha de Andrade, 1981, p. 85)

Esta questão tem uma história mais longa, já que se articula com a polêmica em torno das gramáticas latinas, que antecede as reformas pombalinas e que está na sua gênese.

Que questão se encontrava no cerne desta polêmica?

As controvérsias diziam respeito ao método de ensino da Gramática Latina e uma das maiores polêmicas se travava justamente em torno à língua em que se deveria desenvolver o seu ensino, em Latim ou em língua vernácula, questão algumas vezes reduzida, na historiografia a respeito, a uma mera simplificação e agilização deste ensino. Ora, tal questão, a meu ver, expressa muito mais do que isso, como se pretende mostrar a seguir.

\section{A polêmica sobre as gramáticas latinas}

A importância dessa polêmica para o encaminhamento dado por Pombal à reforma dos estudos menores pode ser avaliada pela afirmação que se segue de Ramos de Carvalho:

As diretrizes e os problemas que emergiram das polêmicas causadas pelo Verdadeiro Método de Estudar e pelo Novo Método de Gramática Latina foram transformados, por força da situação criada com a expulsão dos jesuítas, nos princípios orientadores da política pombalina em relação aos estudos menores. (Carvalho, 1978, p. 78-79)

Com efeito, o Alvará Régio de 1759 não só viria a adotar o novo método proposto pela gramática dos oratorianos e proibindo-se, expressamente, a utilização da gramática adotada nos colégios jesuítas, como as Instruções para os Professores de Gramática Latina usariam dos mesmos argumentos de que se serviram os defensores das novas gramáticas, para justificar a o ensino da gramática latina em língua vernácula.

Foi na primeira metade do século 18 que a Companhia de Jesus, em Portugal, se defrontou com a concorrência de uma outra ordem religiosa, a Congregação do Oratório, cujos padres começam a ocupar um lugar ascendente na vida cultural portuguesa, claramente apoiados por $\mathrm{D}$. João $\mathrm{V}$, que lhes concedeu privilégios negados aos jesuítas ${ }^{12}$.

Referindo-se ao papel exercido em Portugal por esses padres, Ramos de Carvalho (1978) chega a compará-los aos padres de Port Royal, na França, e afirma, peremptoriamente, terem sido eles quem, "por suas escolas, contribuíram poderosamente

\footnotetext{
${ }^{12}$ Para Rômulo de Carvalho (2001), a movimentação cultural no Portugal da primeira metade do século 18 teria sido de tal ordem, que seria justo situar no reinado de $D$. João $V$ o início do processo de atualização cultural da sociedade portuguesa, do que datá-lo das reformas pombalinas.
} 
para solapar o imenso prestígio que, há quase dois séculos, gozavam os jesuítas nos domínios do ensino português" (p. 69). Para este autor:

Foi nos seus cursos, aos quais comparecia a nobreza sequiosa de novidade e até o próprio $D$ João $V$, que a filosofia moderna encontrou abrigo com uma aula de física experimental; foram destes mesmos cursos que surgiram a nova gramática do Pe Antonio Pereira de Figueiredo e a lógica reformada Instrução sobre a Lógica ou Diálogo sobre a Filosofia Racional, do oratoriano Manuel Alvarez, que ao lado da Recreação Filosófica, do Pe Teodoro de Almeida, também oratoriano, contribuíram de maneira ponderável para a renovação da mentalidade portuguesa. (Ramos de Carvalho, 1978, p. 69-70)

A oposição da Congregação do Oratório à Companhia de Jesus tomou um vulto particular com a questão levantada contra a Gramática Latina do jesuíta Manuel Álvares, amplamente utilizada em toda a Europa e na América portuguesa, e perpetuada em sucessivas edições. Esta Gramática, utilizada particularmente nos colégios jesuítas, passa a ser criticada e repudiada pelos oratorianos que a ela opuseram o Novo método pra se aprender Gramática Latina ordenado para uso das escolas da Congregação do Oratório da Casa de Nossa Senhora das Necessidades, cuja primeira edição é de 1746. Como assinala Rômulo de Carvalho (2001), essa questão teve um eco extraordinário na vida cultural portuguesa e motivou o aparecimento de um sem número de escritos polêmicos, publicados pelos vários autores vinculados a cada uma das facções que se defrontavam.

Reação mais violenta e mais profunda esboçou-se contra o Verdadeiro método de estudar para ser útil à República e à Igreja: proporcionado ao estilo e necessidade de Portugal, de Luiz Antonio Verney, publicado pela primeira vez, anonimamente, no mesmo ano de 1746. Verney é unanimemente reconhecido como o principal expoente do lluminismo português e sua influência sobre as reformas pombalinas, e não só as reformas do ensino, é hoje considerada inegável pelos historiadores que se debruçam sobre essa temática. A meu ver, o próprio título da obra de Verney já é uma espécie de síntese do que se afirmou acima sobre as peculiaridades do pombalismo, enquanto expressão do lluminismo português.

Foi especialmente significativo encontrar numa das obras de Banha de Andrade sobre Verney (1980), uma das únicas referências à documentação em estudo que de início se conseguiu localizar.

Com o objetivo explícito de estabelecer a projeção da obra de Verney na reforma pombalina dos estudos, o autor estabelece uma comparação entre o alvará de $1770^{13} \mathrm{e}$ alguns trechos do Verdadeiro método de estudar, apontando para a evidente aproximação entre as idéias de Verney e a argumentação proposta no alvará. Para Banha de Andrade: "O alvará de D. José vinca bem o papel das línguas nacionais, como veículo da cultura iluminista" (1980, p. 57).

É igualmente significativo que a aproximação se estenda ao alvará de 1759 e às instruções para os professores de Gramática Latina no que se refere às mudanças

\footnotetext{
${ }^{13}$ É significativo que, pela referência citada por Banha de Andrade, o alvará tenha sido publicado na própria Gramática da Língua Portuguesa de Antonio Joze dos Reis Lobato, numa edição da Of. Régia de 1771.
} 
propostas também no seu ensino, a meu ver, coerentes com o lugar atribuído às línguas nacionais, particularmente ao português. De fato, o alvará de 1770 representa o aprofundamento de algumas idéias já presentes na regulamentação anterior, que foi, talvez, mais prudente na introdução de mudanças nos conteúdos de ensino.

A esse respeito, parece-me importante transcrever alguns trechos das Cartas Primeira e Segunda do Verdadeiro método de estudar, cuja aproximação com a regulamentação posterior das reformas se torna evidente.

Da Carta Primeira, sobre o estudo da língua e da gramática portuguesa:

A gramática é a arte de escrever e falar corretamente. Todos aprendem a sua língua no berço; mas se acaso se contentam com essa notícia, nunca falarão como homens doutos. [...] Isto suposto, julgo que este deve ser o primeiro estudo da Mocidade, e que a primeira coisa que se the deve apresentar é uma Gramática da sua língua, curta e clara; porque neste particular, a voz do Mestre faz mais que os preceitos. (Verney, 1949, p. 2635)

Da Carta Segunda, sobre o estudo da gramática latina:

Ora convém todos os homens de bom juízo e que tem visto países estrangeiros e lido sobre alguma coisa, convém, digo, que qualquer Gramática de uma língua que não é nacional se deve explicar na língua que um homem sabe. [...] Finalmente, a Gramática Latina para os Portugueses deve ser em Português. (Verney, 1949, p. 139-142)

Não é possível deixar de perceber nessas propostas aquilo que Ramos de Carvalho (1978) qualifica como um "tácito reconhecimento", por parte de Verney, "do estado de maioridade da língua portuguesa" (p. 64). Com efeito, as mudanças propostas e incorporadas, de forma explícita, na lei e alvará de 1770, implicam na atribuição de um novo status à Língua Portuguesa e à própria Língua Latina. Se da primeira se reconhece o estado de maioridade, que permite a sua equiparação às línguas clássicas e que legitima a sua inclusão no currículo dos estudos secundários, especificamente o ensino da sua gramática, a segunda passa a ocupar um lugar diferenciado das línguas modernas, justificando-se a sua permanência no currículo muito mais pelo seu caráter formativo.

É dessa perspectiva que Ramos de Carvalho afirma que "esta valorização da língua portuguesa não é estranha à reforma da latinidade proposta por Luiz Antonio Verney" (1978, p. 64). Para este autor:

nesta altura da história das instituições educacionais, o latim deixava de ser a língua exclusiva dos conhecimentos doutos para enriquecer-se como matéria de uma formação, até então insubstituível, que, sem deixar de ser útil, atendia aos reclamos de uma cultura que não alcançara ainda o âmago das contradições da crise a que foi lançada. (Carvalho, 1978, p. 66)

A proibição da utilização dos textos recentes em Latim, no caso, especificamente, documentos da Igreja, é uma outra estratégia que também pode ser lida desse ponto de vista, confirmando as observações de Anderson (1989) sobre o processo de dessacralização da língua, por meio do qual as ditas línguas sagradas: o Latim, o Grego e 
o Hebreu foram obrigadas a conviver com as línguas vulgares, compartilhando com elas um status intra-mundano. Essa foi uma das mudanças que, na perspectiva do autor, possibilitaram o nascimento da comunidade imaginada da nação.

\section{Conclusão}

Para finalizar, cumpre destacar que esse processo de valorização da língua portuguesa, bem como das demais línguas vernáculas, no âmbito das reformas pombalinas, não se encerra com as determinações do Alvará de 1770.

Nessa direção, foi importante evidenciar, na análise desenvolvida sobre o livro de Registo das datas de provisões para professores dos estudos menores (1783-1794) ${ }^{14}$, uma ampliação do espectro das cadeiras, aulas, oferecidas. A esse respeito, há duas observações que parece importante registrar.

A primeira delas se refere à concessão de licença para o ensino de Gramática, Ortografia Portuguesa e Português, como cadeiras claramente distintas do Latim e Gramática Latina. Em 1784 João Pinheiro Freire Cunha recebe licença para lecionar Gramática e Ortografia Portuguesa, em 1787 Latim e Ortografia e, em 1789 Gramática Latina, Gramática e Ortografia Portuguesa. Já João Chapuzet recebe, em 1792, licença para lecionar Língua Francesa, Português e Latim.

A valorização, igualmente, das demais línguas modernas também se reflete nas novas licenças concedidas.

Em 1785 foi concedida, a Guilherme Carlinright, licença de três anos para as cadeiras de Francês, Inglês, Ler e Escrever na cidade de Lisboa. É o primeiro registro de licença concedida a esse tipo de cadeiras. Ao longo do período, outras licenças foram concedidas para as demais línguas modernas, com destaque para as cadeiras de Francês, Inglês e Holandês/Alemão.

Cabe ressaltar que o número de licenças concedidas às cadeiras de Grego e de Francês no período considerado, 1783-1794, é o mesmo, sendo a primeira já prevista em 1759 e, tradicionalmente, aplicada desde o currículo humanístico dos colégios jesuíticos, e a segunda uma língua moderna que não estava prevista nem no Alvará de 1759, nem na lei de 1772.

Assim, embora os marcos legais não se alterem substantivamente, modificações são incluídas no sistema com vistas a responderem às novas necessidades que se apresentam.

\section{Referências}

ANDERSON, Benedict. Nação e consciência nacional. São Paulo: Ática, 1989.

ANDRADE, Antonio Alberto Banha de. Verney e a projecção da sua obra. Bioblioteca Breve/ v. 49. Venda Nova-Amadora: Instituto de Cultura Portuguesa/Secretaria de Estado de Cultura/Ministério da Cultura e da Ciência, 1980.ANDRADE, Antonio Alberto Banha de. A reforma pombalina dos estudos secundários (1759-1771): contribuição para a história da pedagogia em Portugal. Coimbra: Universidade de Coimbra, 1981.

\footnotetext{
${ }^{14}$ ANTT. Real Mesa Censória. Livro 23.
} 
ANDRADE, Antonio Alberto Banha de. A reforma pombalina dos estudos secundários (1759-1771): contribuição para a história da pedagogia em Portugal. Coimbra: Universidade de Coimbra, 1984.

ASSUNÇÃO, Carlos da Costa. Uma leitura da introdução da gramática de Reis Lobato. Revista da Faculdade de Letras da Universidade do Porto, v. 14, 1997, p. 165-181.

BARBOSA, Sara Rogéria Santos. O ensino de gramática latina e a institucionalização da profissão docente. In: OLIVEIRA, Luiz Eduardo (org.). A legislação pombalina sobre o ensino de línguas: suas implicações na educação brasileira (1757-1827). Maceió: Edufal, 2010.

BARBOZA, Giselle Macedo. O alvará de 1770 e o ensino de língua portuguesa. In: OLIVEIRA, Luiz Eduardo (org.). A legislação pombalina sobre o ensino de línguas: suas implicações na educação brasileira (1757-1827). Maceió: Edufal, 2010.

CARDOSO, Tereza Maria Rolo Fachada Levy. As luzes da educação: fundamentos, raízes históricas e prática das aulas régias no Rio de Janeiro. 1759-1834. Bragança Paulista: USF, 2002.

CARVALHO, Laerte Ramos de. As reformas pombalinas da instrução pública. São Paulo: Saraiva/USP, 1978.

CARVALHO, Rômulo de. História do ensino em Portugal: desde a fundação da nacionalidade até o fim do regime de Salazar-Caetano. Lisboa: Fundação Calouste Gulbenkian, 2001.

FALCON, Francisco J. C. A época pombalina. São Paulo: Ática, 1982.

JULIA, Dominique. A cultura escolar como objeto histórico. Revista Brasileira de História da Educação, n. 1, Campinas: Autores Associados, 2001, p. 9-43.

LEMOS, Wagner Gonzaga. Arte da grammatica da lingua portugueza: um compêndio a serviço das reformas de Pombal. In: OLIVEIRA, Luiz Eduardo (org.). A legislação pombalina sobre o ensino de línguas: suas implicações na educação brasileira (17571827). Maceió: Edufal, 2010.

MONCADA, Luiz C. Um iluminista português do século 18: Luiz Antonio Verney. São Paulo: Saraiva, 1941.

NÓVOA, António. Le temps des professeurs: analyse socio-historique de la profession enseignante au Portugal (18-20 siècle). Lisboa: Instituto Nacional de Investigação Científica, 1987.

VERNEY, Luís Antonio. Verdadeiro método de estudar. Lisboa: Livraria Sá da Costa, 1949 .

ANA WALESKA POLLO CAMPOS MENDONÇA é professora de História da Educação dos programas de graduação e pós-graduação do Departamento de Educação da PUC-Rio. Pesquisadora (bolsista de produtividade) do CNPq.

Endereço: Rua Anita Garibaldi, 26/101 - 22041-080 - Rio de Janeiro - RJ - Brasil.

E-mail: awm@puc-rio.br.

Recebido em 2 de fevereiro de 2012.

Aceito em 27 de setembro de 2012. 